\title{
DESIGN AND APPLICATION OF SOLAR TRACKING SYSTEM USING OPTIMIZED FUZZY LOGIC CONTROLLER BY GENETIC ALGORITHM
}

\author{
*Hayrettin TOYLAN, Mechatronics Engineering Department, Faculty of Technology, University of Kirklareli, Turkey, \\ hayrettintoylan@klu.edu.tr, Phone:0505 9169451
}

(iD) https://orcid.org/0000-0001-8542-7254)

Received: 02.11.2019, Accepted: 19.05.2020

*Corresponding author

Research Article

DOI: $10.22531 /$ muglajsci.641904

\begin{abstract}
This study describes an intelligent control algorithm for the solar tracking system (STS) providing maximum performance from the photovoltaic panel according to different sun positions. The solar tracking system is designed as dual axis to increase the efficiency of photovoltaic panels. DC motors are preferred in order to minimize cost and to control the azimuth and zenith angles in the solar tracking system. Fuzzy logic algorithms are used to adjust the speed of these motors to track the sun's position with a high degree of accuracy. After designing a fuzzy logic controller in order to control the motors, membership functions of controller and control rules are simultaneously found by genetic algorithms which is an optimization algorithm based on natural selection and genetic mechanics. As a result in the study, the power performance analysis is compared between a photovoltaic panel positioned on the designed solar tracking system and a photovoltaic panel positioned on the static system. According to comparison results, the photovoltaic panel positioned on the solar tracking system is observed that it shows higher performance at varying rates of depending on the seasons.
\end{abstract}

Keywords: Photovoltaic system, Solar tracking system, Fuzzy Logic, Genetic Algorithm, Optimization

\section{Genetik Algoritma ile Optimize Edilen Bulanık Mantık Denetleyici kullanan Güneş Takip Sistemi Tasarımı ve Uygulaması}

\begin{abstract}
Özet
Bu çalışma, değişen güneş pozisyonlarına göre fotovoltaik panelden maksimum performansı sağlayan güneş takip sistemi için zeki bir kontrol algoritması tanımlar. Güneş Takip Sistemi, fotovoltaik panellerin etkinliğini yükseltmek için çift eksen olarak tasarlandı. Güneş Takip Sisteminde Azimut ve Zenit açılarını kontrol etmek ve maliyetleri minimize etmek için DC motorlar tercih edildi. Güneşin pozisyonunu yüksek doğrulukla izlemek için bu motorların hız kontrollerinde Bulanık Mantık Algoritmaları kullanıldı. Motorları kontrol etmek üzere Bulanık Mantık Denetleyicisinin tasarlanmasından sonra denetleyicinin üyelik fonksiyonları ve kontrol kuralları, doğal seçim ve genetik mekaniği temel alan bir optimizasyon algoritması olan Genetik Algoritmalar tarafindan bulunur. Bu çalışmada sonuç olarak, sabit sistem üzerine pozisyonlanmış fotovoltaik panel ile geliştirilen güneş takip sistemi üzerine pozisyonlanmış fotovoltaik panel arasında güç performansı karşılaştırıldı. Karşılaştırma sonuçlarına göre güneş takip sistemi üzerine pozisyonlanan panel mevsimlere bağlı olarak değișen oranlarda daha yüksek performans gösterdiği gözlemlendi.
\end{abstract}

Anahtar Kelimeler: Fotovoltaik Sistem, Güneș Takip Sistemi, Bulanık Mantık, Genetik Algoritma, Optimizasyon Cite

Toylan, H., (2020). "Design and application of solar tracking system using optimized fuzzy logic controller by genetic algorithm ", Mugla Journal of Science and Technology, 6(1), 136-145.

\section{Introduction}

Solar energy is one of the most common renewable energy sources in recent years [1]. Solar energy technologies can be examined in two main groups. The first of these is Thermal Solar Technologies and Concentrated Solar Power (CSP) systems. The other one 
electro-optical STS are based on the difference in light

\begin{tabular}{|ll}
\hline \multicolumn{2}{l}{ Nomenclature } \\
STS & Solar Tracking System \\
CSP & Concentrated Solar Power \\
PLC & Programmable Logic Controller \\
LDR & Light Dependent Resistors
\end{tabular}

directly into electrical energy through semiconductor materials. Increasing the electricity production of photovoltaic cells depends on several factors. One of these factors is the use of solar tracking systems (STS) that monitor the Sun from sunrise to sunset for maximum energy gain [1].

STS can be single or dual-axis. Single-axis systems enable the movement of the panels in the east-west direction (Azimuth). Dual-axis STS allow movement in both east-west and north-south (Zenith) directions. STS can be divided into three types according to their operating modes: chronological, passive, and active STS [2]. Passive STS are based on the thermal expansion of a matter or shape memory alloys. In the work of Clifford and Eastwood, two aluminum/steel bimetallic strips were used symmetrically on either side of a central horizontal axis, mounted on a wooden frame. Of the bimetallic strips, the strip that is further from the sun absorbs solar radiation, while the other strip remains shaded.

The liquid in one of the two identical cylindrical tubes exposed to the sun's rays from different angles evaporates and a weight difference occurs, thereby moving the photovoltaic panel in one direction [3]. Poulek developed a single-axis passive STS based on shape memory alloy. The alloy used acts as a heat engine during the thermal cycle and can easily deform even under low temperatures. When heated above the conversion temperature, it returns to its original state. By using this feature, it was enabled to follow the sun [4]. In his study, Farooqui described a new mechanism for single-axis tracking of box-type solar cookers along the azimuth. The designed system doesn't require any external power source, as the necessary tracking power is produced from the gravitational energy stored in the spring [5]. Natarajan and Srinivas developed passive STS based on gravity mechanism and tested it experimentally. They attempted to minimize the tracking load and error by controlling the dropping rate or filling rate of the liquid in the gravity system [6]. Passive tracking systems operate without any electronic control or motor, without consuming electrical energy, but their accuracy is limited.

In the active STS, optical sensors are used to track the Sun. The position of the sun is defined via the error signals measured by the sensors, and then, the solar panel is rotated towards the Sun [7]. Active STS can be divided into two parts. These are electro-optical and microprocessor-controlled STS. The principles of the
$P V \quad$ Photovoltaic Panel

$P I D$ Proportional, Integral, and Derivative

$D A Q$ Data acquisition

$G A$ Genetic algorithm

DC Direct Current

intensity falling upon two well-positioned photo resistors. An electronic circuit moves the motor in one direction until both photo resistors achieve the same resistance value. To ensure the proper operation of such systems, a highly precise installation is required [8]. Kalogirou designed a single-axial STS consisting of a circuit with three Light Dependent Resistors (LDR) sensors and a DC motor, with this method. The status and position of the Sun were determined by three LDRs. Thanks to the designed circuit, he succeeded in tracking the sun in the east-west direction at a speed of 0.011 rpm [9]. In the study of Sefa et al., an electromechanical mechanism was designed to enabling the solar panels to move in the east-west direction. The movements of the single-axis system were controlled using two LDR. The LDR's were connected in series with each other, and a control circuit was established by removing the connection point in the middle of the resistors. From the results, it was seen that the power collection efficiency of the single-axis tracking system was higher than that of a fixed system [10].

In the microprocessor-controlled STS, the information received from sensors is processed in the control algorithm, and thus, motors are controlled. In their study, Konar and Mandal designed a microprocessorbased single-axis STS for use in a photovoltaic flat type solar panel or with a cylindrical parabolic reflector. To collect maximum solar radiation in these systems, they controlled the azimuth angle with the help of a stepper motor [11] .In their study, Abdallah and Nijmeh designed a dual-axis STS. They granted control of the tracking system by using a PLC controller with an openloop circuit design. In that study, daylight hours were divided into four equal parts in which the engine speeds (degrees/seconds) were determined. Then, the PLC was programmed according to the specified parts and the control of the tracking system was ensured. It was pointed out that the designed dual-axis solar tracking system was $41.34 \%$ more efficient compared to a 32 degree fixed-positioned PV panel [12]. Ferdaus et al. designed and tested a hybrid dual-axis solar tracking system based on both the solar map and light sensorbased continuous tracking mechanism. In their work, they used a light sensor, a position sensor, and a realtime clock. They controlled the stepper motor drives via the microcontroller with the output obtained from these sensors, and they ensured the control of the tracking system. They stated that their systems were $44.44 \%$ more efficient [13]. Yao et al. developed two different 
solar tracking systems, which are called the normal tracking strategy and daily adjustment strategy. They made the power comparison of the PV panel mounted on a STS controlled by these two different strategies and the PV panel mounted on a fixed system. It is seen that the normal tracking strategy shows high performance with a tracking error of $0.15^{\circ}$. The other strategy may have bigger tracking errors, but its annual average for horizontal PV systems is estimated to be under $1.3 \%$. In their studies, researchers attempted to demonstrate that high-precision tracking would lead to extra operating costs, hence, with a simple and cost-effective tracking strategy, small tracking errors could be ignored [14]. When different researches are examined, it is seen that the STS is controlled using different algorithms. Yazidi et al. controlled the DC motor, which ensures the movement of the STS, using both the PID (Proportional, Integral, and Derivative) control algorithm and fuzzy logic. With PID control, the response of the system is very slow since it takes almost 17 seconds. It was stated that this time could be decreased using fuzzy logic control, but it could not be validated experimentally [15].

The chronological STS is a time-based tracking system that moves at a fixed rate throughout the day, even in different months [2]. The controller calculates the position of the sun from formulas or algorithms using the time/date and geographic information to control the motors. Edwards researched the procedure of a computer based STS which controls paraboloidal collectors. The system computer changed the speed of each of the collector actuators at regular intervals over the day [16].

Alata et al. developed a time controlled sun tracking system. They based the control of three different tracking systems which they designed, on fuzzy logic. Alata et al. determined the position of the sun without using any sensors with the help of equations describing the motion of the sun across the sky, and included mathematical formulations in their studies [17]. Batayneh et al. introduced single-axis STS that only actuates three times a day in the azimuthal plane to follow the sun. Moreover, experimental results showed that collected approximately $91-94 \%$ of a solar radiation of a STS tracking the sun in only three times a day in the azimuthal plane [18]. However, the study provides this success in the summer months. In seasonal changes, the zenith angle adjustment as manual will be needed according to sun position. Kuttybay et al. an intelligent automated STS designed to increase the efficiency of solar energy in PV. They aimed to provide the best performance of the panels in various weather conditions with designed system. This algorithm brings to horizontal plane the position of PV panel in cloudy weather conditions. Experimental results showed that energy generated in cloudy weather using proposed method increased by $18 \%$ [19]. In this method, as a disadvantage, the rays reflected from the ground are not collected by the PV panel [20].
The literature showed that the double-axis tracker could improve more than single-axis tracker the electricity production efficiency of the PV system by tracking the position of the sun. Moreover, in these studies, it was seen that this was possible thanks to the successful application of different methods that provide control of the STS. Therefore, a dual-axis solar tracking system was designed and developed in this study. The originality of this article is that the Fuzzy logic controller, whose membership parameters are optimized with GA (Genetic Algorithm), is used to control the STS. GA is one of the heuristic optimization approaches, without the experience of a human operator or the knowledge of a control engineer. Thanks to this method, it is ensured that the sun rays are perpendicular to the plane of the PV panel during the day. In addition that reflectance losses due to the incidence angle are thus minimized and electricity production efficiency of the PV panel is raised

This system is an active STS and a closed-loop control method was used. The position of the sun was obtained from mathematical equations according to the geographical location and date/time information of Pinarhisar Vocational School of Kirklareli University. Positioning the photovoltaic panels as perpendicular to the sun according to the determined sun position to maximize their effectiveness was achieved through the defined algorithms. This system was characterized by a quite simple electromechanical installation, and the results were investigated experimentally.

\section{Design of the Solar Tracking System}

In this study, the dual-axis STS was designed and developed considering the optimum performance as well as the investment costs (Fig. 2). The STS consists of the following: one DC gear motor to adjust azimuth angle, one DC Linear Actuator which adjusts the zenith angle, Dual-channel motor driver (MC33926), two reed relays acting as encoders connected to DC motors, Arduino Mega Card acting as DAQ (data acquisition) card, a PC, and a mechanical design capable of carrying four 120W PV panels. The algorithms enabling the control of the tracking system were developed via MATLAB software.

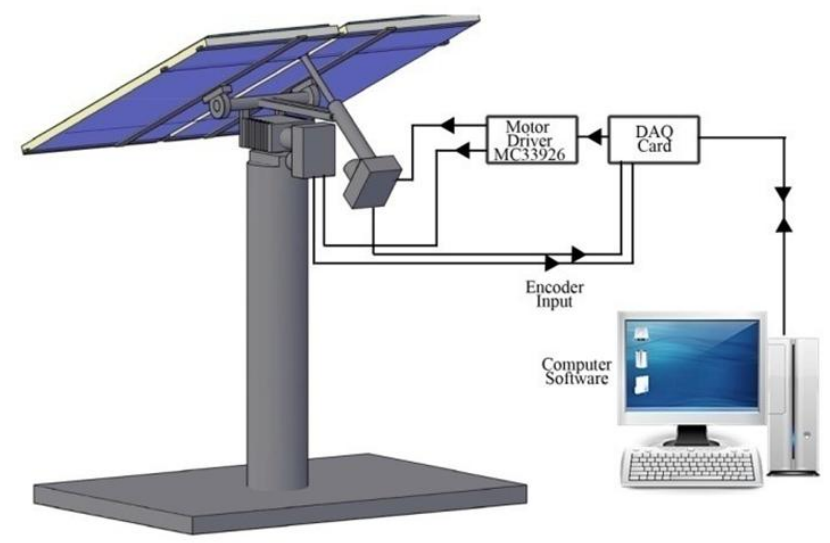

Figure 2. Dual-axis solar tracking system 


\subsection{Calculating the Position of the Sun}

It is possible to obtain maximum output power from the panel by exposing the solar panel surface to maximum sunshine. This is achieved by the solar radiation reaching the panel surface perpendicularly. The position of the sun has to be known in order to turn the panel surface to the point where the rays of the sun come from. The instantaneous positions of the sun for a whole year were determined by mathematical equations, by considering the longitude, latitude, and local time information of the special area where the panel would be placed. According to the results of the equations, azimuth (East-West) and zenith (High-Low) angles, which are the angle parameters of the system, are determined (Fig. 3).

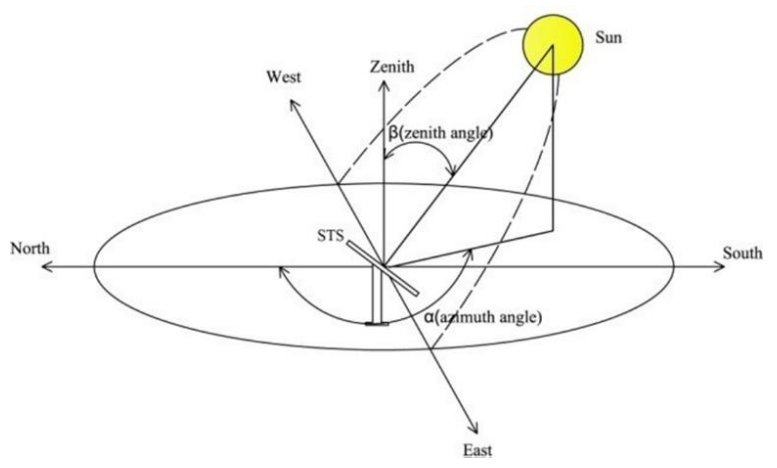

Figure 3. Sun's position

The zenith angle $(\theta z)$ is the angle between direct solar radiation and the normal of the horizontal surface.

It is calculated as follows [21];

$$
\cos \left(\theta_{Z}\right)=\sin (\varphi) \cdot \sin (\delta)+\cos (\varphi) \cdot \cos (\delta) \cdot \cos (h)
$$

$\varphi$ is the latitude angle. $\delta$ is the declination angle and is the angle between the ecliptic and the equatorial plane of the earth. It is calculated as follows [2];

$$
\delta=23.45 \cdot \sin [(360 / 365) \cdot(284+N)]
$$

$N$ is the number of days as of January. $h$ (hour angle) is the angle between the longitude where the solar rays are present and the longitude of the relevant location (Alata et al. 2015).

$$
h=15 .(G S-12)
$$

GS is the sundial. The solar azimuth angle $(\gamma s)$ is the angle that the projection of the Sun-Earth direction on the horizontal plane makes with the south direction [21];

$$
\gamma_{s}=\cos ^{-1}[(\cos \theta z \cdot \sin \varphi-\sin \delta) /(\sin \theta z \cdot \cos \varphi)]
$$

\section{Optimized Fuzzy Logic Controller}

The first information about fuzzy logic is based on Lotfi A. Zadeh's work in 1965 [22]. Fuzzy logic is a nonlinear control method that attempts to apply expert knowledge of an experienced user to the design of a fuzzy-based controller. The fuzzy logic controller consists of four main components [23].
The fuzzifier converting crisp (real-valued) inputs into fuzzy sets to activate the rules

The rule base converting controller behavior into the defining rules using a set of IF-THEN statements

The inference engine mapping the input fuzzy sets to the output fuzzy sets by applying rules

The defuzzifier converting the output fuzzy values to the crisp output

The speed control of the two DC motors in the STS will be maintained by fuzzy logic. The error $e(t)$ between the position of the sun and position of the panel during system operation and the change of error $d e(t)$ constitute the inputs for the controller. The controller has one output used to send PWM signals to the motors.

$$
\begin{aligned}
& e(t)=r(t)-y(t) \\
& d e(t)=e(t)-e(t-1)
\end{aligned}
$$

Here, $r(t)$ identifies the reference signal, and $y(t)$ signifies the feedback signal. In fuzzy set theory, the value range of membership functions is determined between $[0,1]$. $\mu \mathrm{A}(\mathrm{x})$; is the membership function for the fuzzy set. The value this function will get is called the membership value the element $x$ in the fuzzy set $A$ and is shown as $\quad \mu \mathrm{A}(\mathrm{x})=[0,1]$. The function that maps the elements of a fuzzy set to a number in this range is called the "membership function" [24, 25]. In the present study, a triangular membership function with five members is defined. The membership function used to adjust the zenith angle is shown in fig. 4 . The zenith angle has 85 degrees of movability due to its mechanical design. The membership function used to adjust the azimuth angle is shown in fig. 5. The azimuth angle has 226 degrees of movability due to its mechanical design.
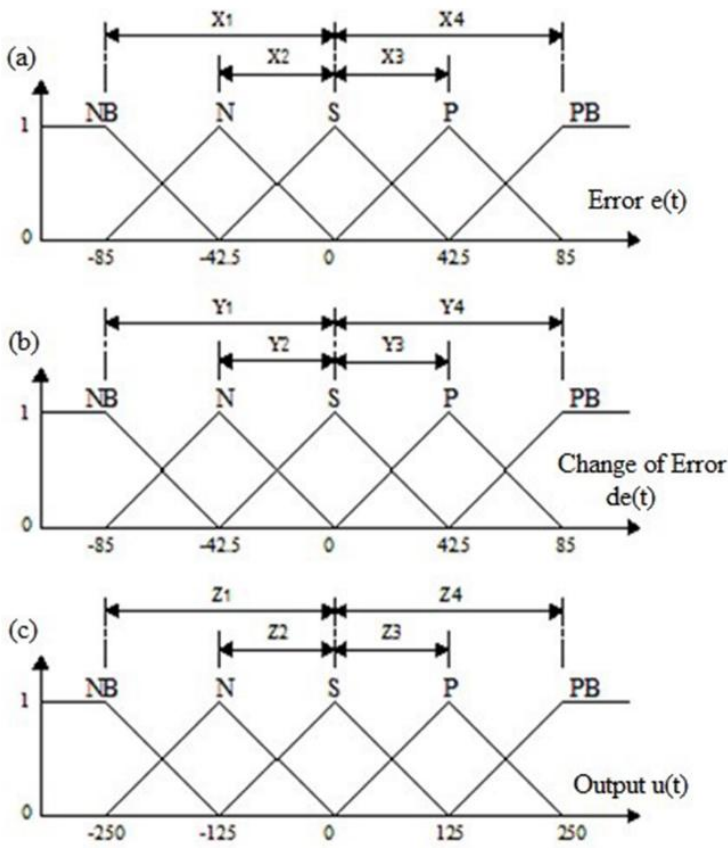

Figure 4. Membership functions for Zenith angle; (a) error, (b) change of error, (c) output 
When calculating the azimuth angle, attention should be paid to the declination angle. This angle is the $23^{\circ} 27^{\prime}$ angle that the earth's rotational axis makes with the normal of the ecliptic plane. Because of this angle, on September 23 and March 21, the Sun rises due east and sets due west on our horizon. On December 21 and June 21, a difference of about 23 degrees occurs between the angles where the sun rises and sets, compared to September 23 and March 21.Considering the declination angle, the azimuth angle rotational ability of the STS was determined as $226^{\circ}$.
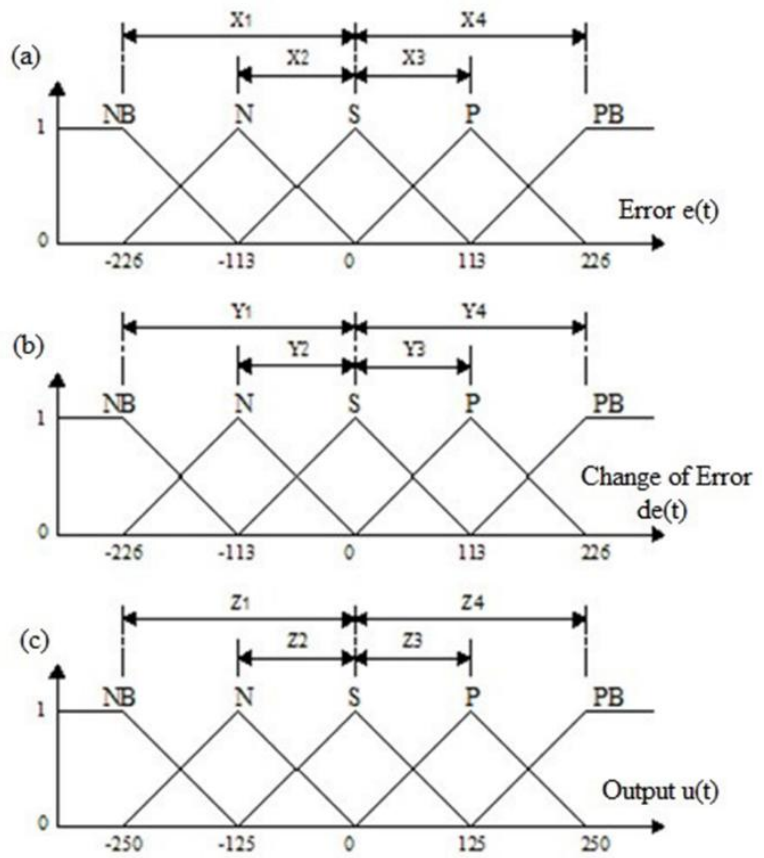

Figure. 5. Membership functions for Azimuth angle (a) error, (b) change of error, (c) output

GA can be used to find optimal values of fuzzy logic parameters such as membership functions and rule bases [26]. A genetic algorithm is a search and optimization method based on the principles of natural selection. The solution to a problem via the GA is found by putting the problem through a virtual evolution process. In this way, the required optimal solution is sought by scanning a certain part of the solution space and not the whole. Genetic algorithms do not operate with the parameter set but their coded versions [27].

Genetic algorithms, unlike other traditional optimization methods;

Take into account many points in the GA search space, not a single point.

Operate with character strings that represent GA parameter sets, not with the parameters themselves.

Use the rules of probability in GA searches, not fixed rules [26].

\subsection{Coding of Fuzzy Logic Parameters}

The genetic algorithm was used to optimize and develop the fuzzy logic algorithm. Fuzzy logic membership function parameters were obtained through the Genetic-algorithms-based software written via Matlab program. Firstly, the central parameter values of the triangle membership functions in decimal form (X1, X2, $\mathrm{X} 3, \ldots, \mathrm{Z} 4$ ) were converted to binary form(Fig. 6). Then, a population consisting of chromosomes (individuals) which represent many solutions to the problem $(\mathrm{A} 1, \ldots$, A100) was created.

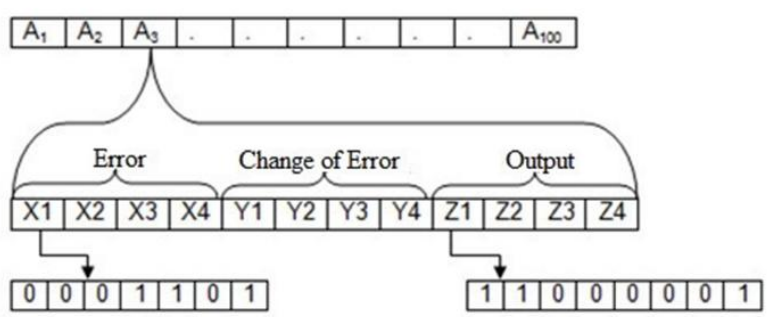

Figure 6. Structure of zenith angle chromosomes used with binary codes

All encoded parameters are combined and chromosomes, consisting of (8 center points $x 7$ bits) 2 inputs $+(4$ center points $\times 8$ bits $)$ single output $=88$ bits (gen), are created for the zenith angle. As for the azimuth angle, chromosomes consist of (8 center points x 8 bits $) 2$ inputs + ( 4 center points $x 8$ bits $)$ single output $=96$ bits. The next process is to achieve the optimal parameter values by following the steps outlined in the flow chart (Fig. 7).

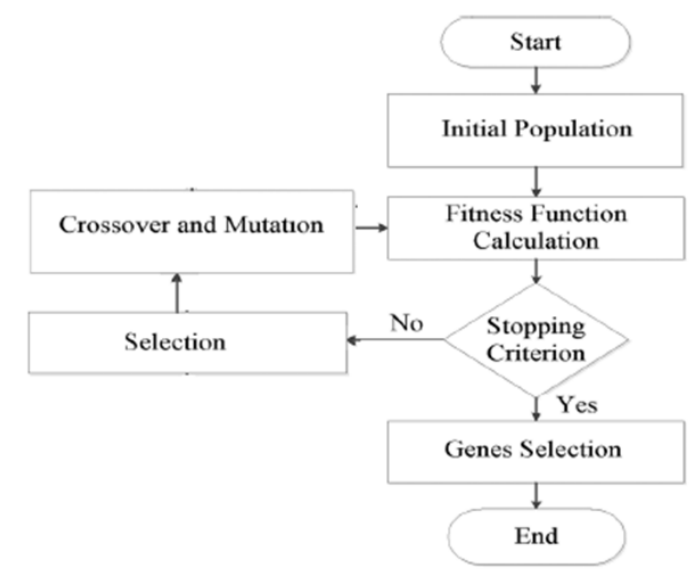

Figure 7. Genetic Algorithm flow chart [26]

Fitness function plays an important role in reaching the optimal parameter values. The fitness of each chromosome in the population is calculated according to fitness function and sorted by the computed result. In this study, optimization applied with GA is based on minimizing the panel position error. The fitness function chosen is given by:

$$
F F=\int_{0}^{t}|e| \cdot d t
$$


Where $e(t)=r(t)-y(t)$

Here, $r(t)$ defines the reference signal and $y(t)$ defines the feedback signal.

The chromosomes whose fitness values are close to the result are defined as successful individuals. Due to the structure of genetic algorithms, the closer the chromosome's fitness value to the result, the higher the chance of the chromosome to survive and reproduce. During these processes, when creating new chromosomes or new individuals, the selection methods that will increase the likelihood of selection of individuals with high fitness values are used. In this study, the roulette wheel selection method was employed. Until a stopping criterion is met, new chromosomes are obtained from the most successful chromosomes in the initially generated population. As new chromosomes are obtained, individuals undergo crossing and mutation processes.

To obtain two new generation individuals, chromosomes selected from the mating pool of successful individuals are put through the crossing process. The crossover rate determines how many chromosomes in a population will be subjected to the crossing process. In this study, the single point crossover was utilized as the crossover method. As the name suggests, chromosomes are cut at corresponding points, and the cut parts are exchanged. The resulting new chromosomes contain the characteristics of both chromosomes.

After the crossing over process, the chromosomes are subjected to the process of mutation to prevent the newly produced chromosomes from repeating themselves. In the mutation process, small changes are made randomly in the individuals forming the chromosomes. In mutation, if the bits of the chromosome are " 1 ", they are changed to " 0 ", if " 0 ", to "1". The number of genes modified is as many as the ratio of mutation. Finally, new individuals obtained from crossing and mutation processes replace former individuals in the newly generated population. Table 1 shows parameters of the genetic algorithm used in the STS.

Table 1. Parameters of the genetic algorithm used.

\begin{tabular}{lc}
\hline Parameter & Value \\
\hline Representation & Binary \\
Population size & 100 \\
Chromosome size & 88 \\
Generations & 100 \\
Selection method & Roulette \\
wheel & \\
Rate of mutation & 0.02 \\
Rate of crossover & 0.8 \\
Crossover method & Single-point
\end{tabular}

\section{Results and Discussion}

In this study, a dual-axis STS, which is controlled by the fuzzy logic algorithm optimized by the GA, was designed (Fig.8). To compare the performance of the STS, another photovoltaic panel, which was fixedly positioned at 32 degrees in the south direction, was placed at a close point (Fig.9).

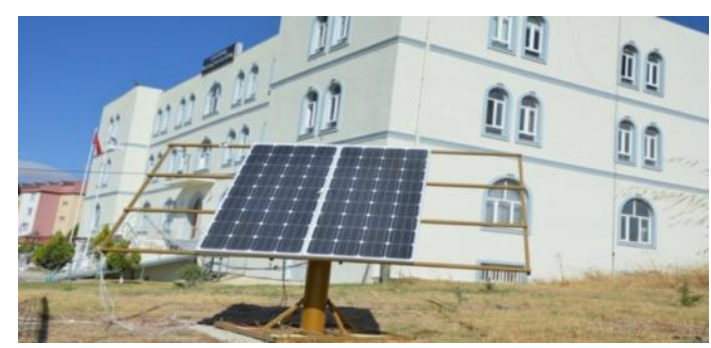

Figure 8. Solar Tracking System
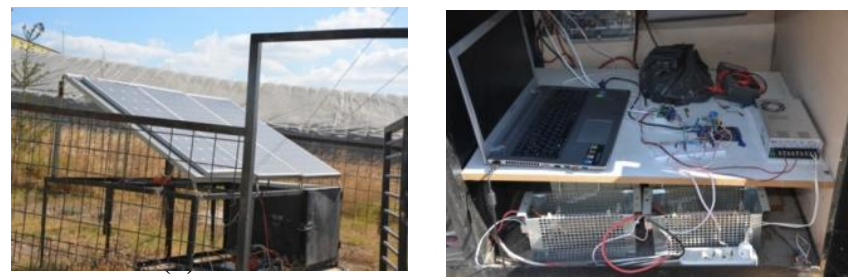

Figure 9. (a) Fixed photovoltaic panel view,(b) Control equipment

With the speed control of 2 DC motors, it was provided that the STS could bring the photovoltaic panel to a position perpendicular to the sun. These motors were used to control the azimuth and zenith angles of the system. Although similar fuzzy logic control approaches were used for these two motors, these control algorithms had different membership function parameters. Therefore, membership function parameters were determined separately for two motors, and a control algorithm was applied. The optimal or closest optimal membership function parameters of the Fuzzy logic algorithm, which maintains control of the motors, were determined by the GA optimization approach, without the need for expert users or control engineers' knowledge. Fuzzy logic membership function parameters were changed after obtaining the chromosome which reached the optimum solution using the developed GA software. Accordingly, Fig.10 and Fig.11 show the diagrams of the fuzzy logic membership functions of the DC motors controlling zenith and azimuth angles, respectively. 


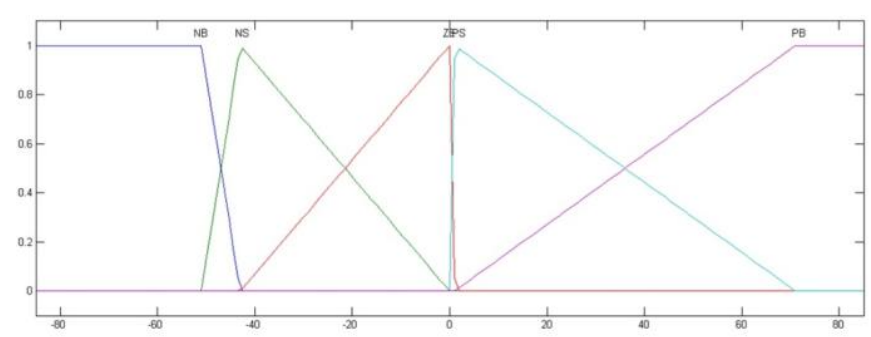

(a)

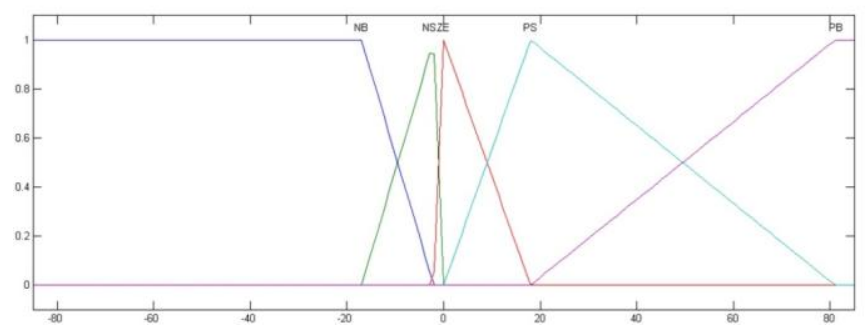

(b)

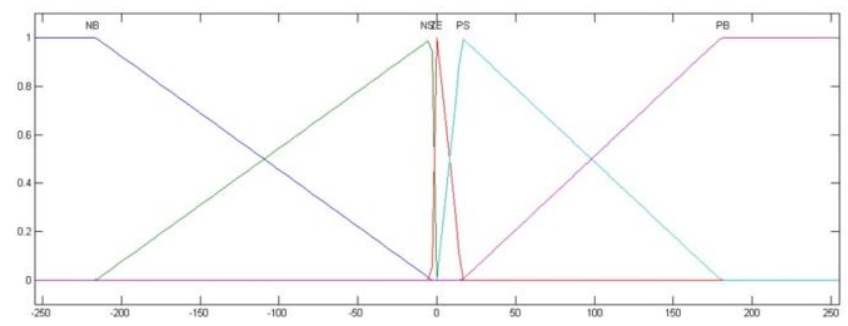

(c)

Figure 10. Optimal membership functions obtained for the zenith angle variable error (a), Change of error (b), and output (c).

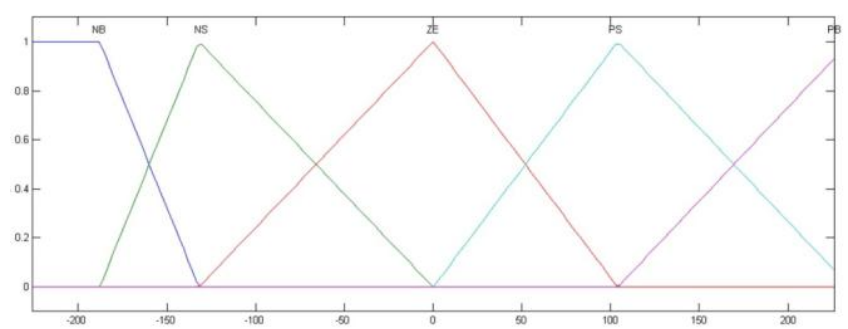

(a)

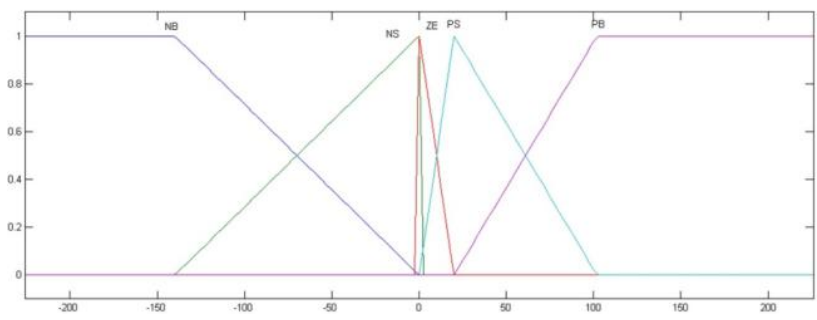

(b)

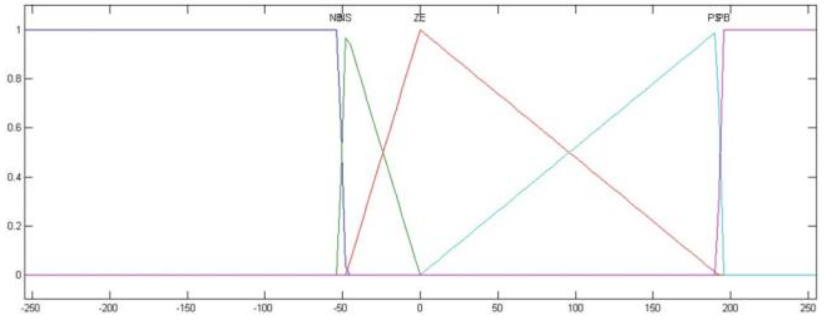

(c)

Figure 11.0ptimal membership functions obtained for the azimuth angle variable error (a), Change of error (b), and Output(c).

In Fig. 10 and fig.11, the sum of the values of the output membership degrees at each point along the vertical axis was kept equal to 1 , to avoid any loss in the data space. For the membership functions of the fuzzy logic control algorithm that maintains control of the DC motors, there are a total of five different verbal variables, which are Negative Big (NB), Negative Small (NS), Zero (ZO), Positive Small (PS), and Positive Big (PB).Table 2 shows 25 rules used corresponding to the error and the change in error.

Table 2. Fuzzy logic rule table

\begin{tabular}{|c|c|}
\hline \multirow[t]{2}{*}{ Output(u) } & Change in Error (de) \\
\hline & NB NS ZO PS PB \\
\hline Error(e) NB & NB NB NB NS ZO \\
\hline NS & NB NB NS ZO PS \\
\hline $\mathrm{ZO}$ & NB NS ZO PS PB \\
\hline PS & NS $\mathrm{ZO} \quad \mathrm{PS} \quad \mathrm{PB} \quad \mathrm{PB}$ \\
\hline PB & $\mathrm{ZO}$ PS $\mathrm{PB}$ PB $\mathrm{PB}$ \\
\hline
\end{tabular}

The fuzzy logic system in Matlab software can work with two different inference methods, Mamdani and Sugeno. In this study, Mamdani inference method, which is closer to human behavior, is preferred. Fig. 12 (a) and Fig.12 (b) show control surfaces for the fuzzy model of zenith angle and azimuth angle

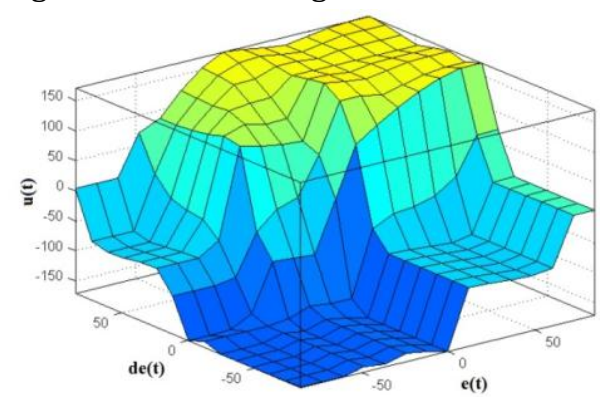

(a)

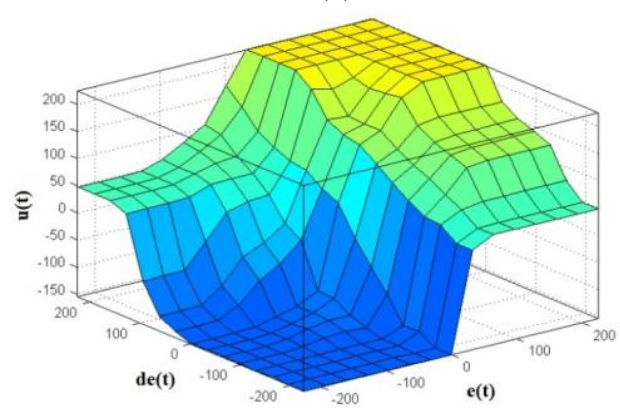


(b)

Figure 12. Control surfaces for the fuzzy model of zenith angle (a) and azimuth angle (b) found by the GA.

Thanks to the software implemented, the system succeeded in ensuring that the panels were positioned perpendicular to the sun during the day. While doing this, the position of the sun was determined via the algorithm, not the sensors. By using the latitude, longitude and altitude information of the location where the system was positioned and the date and time information as the input data, the orbit of the sun was determined by mathematical equations. This technique provides more safe results compared to the systems using sensors. It enabled to prevent external conditions and disruptive effects such as overcast weather, pollution, and rain from destabilizing the system.

The performance analysis of the fixed panels with the developed STS (Solar Tracking System) was carried out on a day in July when the weather was clear (fig.13).The current and voltage values generated by the $120 \mathrm{~W}$ panel mounted on the STS and the photovoltaic panels placed on a 32 degree fixed system were measured every two minutes during the day, and 720 power ratings were obtained for each.

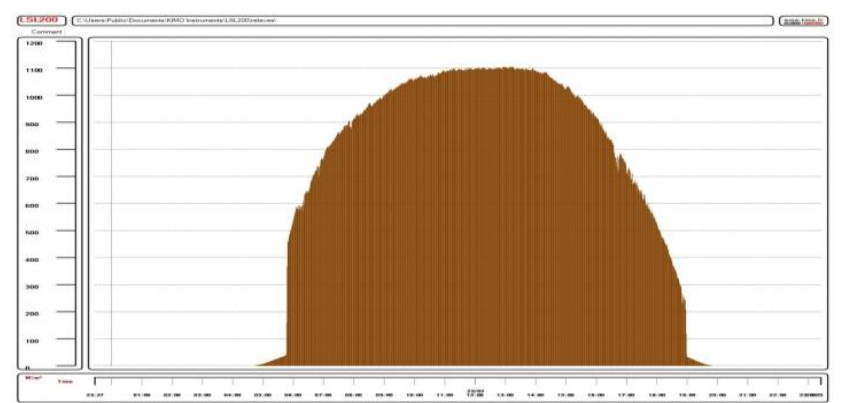

Figure 13. Instantaneous solar radiation value (Date: 23.07.2015)

Fig. 14 shows the power generated by both the fixedposition photovoltaic system and the STS during the day. The power ratios generated by the systems vary momentarily depending on the position of the sun and clouding sky. Despite the sunrise at 07:02 in the morning, production was minimal since the fixedposition photovoltaic system could not be exposed to solar radiation. On the other hand, at the same hour, the photovoltaic panel positioned on the STS showed an instantaneous value of 82.73 Watts. It is seen from the detailed power graph that this value changes momentarily in the range of 73.87 Watt and 57.65 Watt, depending on the clouding in the weather. Another detailed power graph shows the changes in the power generated by the photovoltaic panels mounted on both the fixed system and the STS, in case of clouding weather conditions at 16:12.

As a result, by means of the designed and developed STS, solar energy can be benefited with maximum efficiency in the presence of the sun. In this way, sun rays are used most efficiently during the day, thus creating an opportunity of benefiting solar energy with maximum value. It is concluded that by employing the STS, the obtained power efficiency is $45.87 \%$ higher at the measurement date, compared to the fixed system. To compare the acquired results, the power estimation values of the fixed and dual-axis photovoltaic panels were obtained for the position of our photovoltaic panels, using the European Commission's Photovoltaic Geographical Information System Interactive Maps (Table 3).

Table 3. Average daily electricity production for presented two systems (kWh)

\begin{tabular}{lcc}
\hline Month & Fixed-position system & Dual-axis STS \\
\hline January & 0.24 & 0.29 \\
February & 0.32 & 0.39 \\
March & 0.45 & 0.55 \\
April & 0.52 & 0.67 \\
May & 0.60 & 0.83 \\
Jun & 0.61 & 0.89 \\
July & 0.64 & 0.91 \\
August & 0.61 & 0.88 \\
September & 0.52 & 0.69 \\
October & 0.41 & 0.52 \\
November & 0.29 & 0.37 \\
December & 0.20 & 0.25
\end{tabular}

Table 3 shows the average daily power generation of a photovoltaic panel with $100 \mathrm{~W}$ nominal power, on a monthly basis if the panel is fixedly positioned by 32 degrees and is mounted on a dual-axis STS. When examining the estimation results, calculations showed that the fixed solar panel would produce daily average energy of $0.64 \mathrm{kWh}$ in July and the panel with dual-axis STS would produce daily average energy of $0.91 \mathrm{kWh}$ in the same month. Here, it is seen that the panel with dual-axis STS will work $42.18 \%$ more efficiently in comparison with the panel with a fixed axis. This rate rises to the level of $45.9 \%$ in June and $44.2 \%$ in August. As it can be observed, the results obtained from the European Commission's Photovoltaic Geographical Information System and the result we obtained from the system we applied showed close values. 


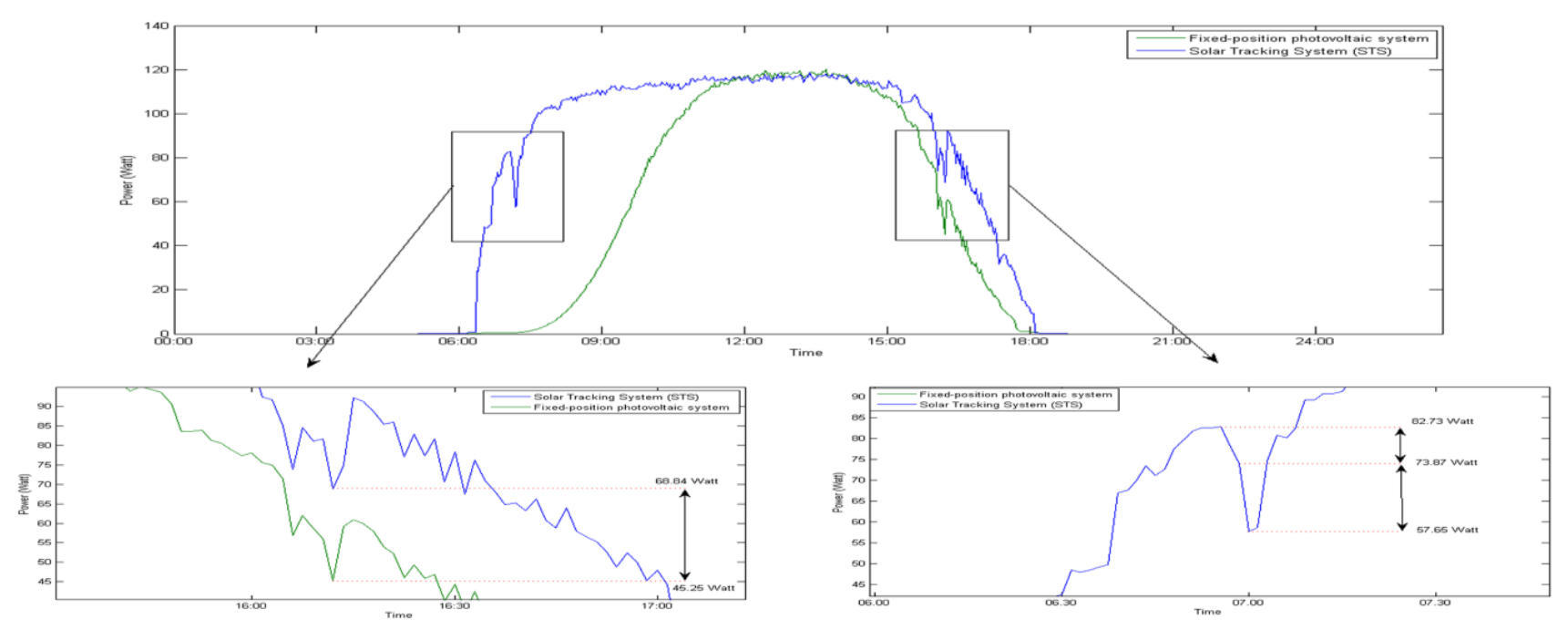

Figure 14. STS and Fixed photovoltaic panel (120W) daily power generation

According to these results, it can be said that when two systems are compared especially in the winter months, efficiency results of the two systems will be close to each other due to the reduced sunshine hours and the weather conditions; and when spring and summer comes, then the difference between system efficiencies will increase.

\section{Conclusion}

In this study, a Fuzzy Logic algorithm was developed for the dual-STS, which enables the sun rays to come perpendicularly to the panel in order to increase the efficiency of the photovoltaic panel. Membership parameters of fuzzy logic algorithm were optimized with GA (Genetic Algorithm) to increase the success of sun tracking of the dual-axis STS. Therefore, the power performance analysis is compared between a photovoltaic panel positioned on the designed solar tracking system and a photovoltaic panel positioned on the static system.

Experimental results showed that the photovoltaic panel yield is likely to increase in the range of $40-45 \%$ in the summer months with a dual-axis STS in Kirklareli city, Turkey. This rate is expected decreasing to the level of about $20 \%$ in the winter months. Some researches in the literature support the findings of the current study. Electric yield may be increased up to $25-45 \%$ compared to fixed structures with an optimum tilt angle using the dual axis STS [20, 28].

Using latitude, longitude, and altitude information of the location where the STS was located and date and time information as input, the position of the sun was determined by mathematical equations. According to the results of this equation, the sun was tracked by STS during the day. There is a disadvantage tracking the sun continuously regardless of the weather conditions. Irradiance of the sun come diffuse from the sky dome without any direction in overcast days. In such moments, tracking the sun is ineffective, but it can be more effective to orientate the panels to horizontal position. However, the irradiance reflected from the ground cannot be collected by the panel in a horizontal position. Suggestions for future studies, it is recommend to develop a tracking algorithm by considering the weather conditions with appropriate sensors to examine the impact of that situation.

\section{References}

[1] Sharaf Eldin, S.A., Abd-Elhady, M.S., Kandil, H.A., "Feasibility of solar tracking systems for PV panels in hot and cold regions." Renewable Energy, 85, 22823, 2016.

[2] Vieira, R.G., Guerra, F.K.O.M.V., Vale, M.R.B.G., Araújo,M.M., "Comparative performance analysis between static solar panels and single-axis tracking system on a hot climate region near to the equator." Renewable and Sustainable Energy Reviews, 64, 672681, 2016

[3] Clifford, M.J., and Eastwood, D., "Design of a novel passive solar tracker." Sol Energy, 77(3), 269-80, 2004.

[4] Poulek V., "Testing the new solar tracker with shape memory alloy actors." Proc. 24th Conf. IEEE Photovoltaic Specialists Conference, 1131-1133, 1994.

[5] Zaki Farooqui, S., "A gravity based tracking system for box type solar cookers." Solar Energy, 92, 62-68, 2013.

[6] Natarajan, M. and Srinivas, T., "Experimental and simulation studies on a novel gravity based passive tracking system for a linear solar concentrating collector." Renewable Energy, 105, 312-323, 2017.

[7] Quesada, G., Laura Guillon L., Rousse, D. R., Mehrtash, M., Dutil, Y., Paradis, P., "Tracking strategy for photovoltaic solar systems in high latitudes." Energy Conversion and Management, 103, 147-156, 2015.

[8] Bentaher, H., Kaich, H., Ayadi N., Ben Hmouda M., Maalej, A., Lemmer, U., "A simple tracking system to 
monitor solar PV panels." Energy Conversion and Management,78, 872-875, 2014

[9] Kalogirou, S.A., "Design andconstruction of a oneaxis sun-tracking." Sol Energy, 57(6), 465-469, 1996.

[10] Sefa, I., Demirtas, M., Çolak, I.,"'Application of oneaxis sun tracking system." Energy Convers Manage, 50, 2709-2718, 2009.

[11] Konar, A., and Mandal, A.K., "Microprocessor based automatic sun-tracker." IEE Proceedings Part A Physical Science Measurement and Instrumentation Manage-ment and Education Reviews,138(4), 237241, 1991.

[12] Abdallah, S., "Nijmeh S, Two axes sun tracking system with PLC control." Energy Conversion and Management,45,1931-1939, 2004.

[13] Ferdaus, R.A., Asif Mohammed, M., Rahman, S., Salehin, S., and AbdulMannan, M., "Energy Efficient Hybrid Dual Axis Solar Tracking System." Journal of Renewable Energy,2014,1-12, 2014.

[14] Yao,Y., Hu, Y., Gao, S., Yang, G., Du, J., "A multipurpose dual-axis solar tracker with two tracking strategies." Renewable Energy, 72, 88-98, 2014.

[15] Yazidi A., Betin, F.,Notton G., Capolino, G.A., "Low cost two-axis solar tracker with high precision positioning." Environment Identities and Mediterranean Area, ISEIMA '06. First international Symposium on, 9-12 July 2006 Corte-Ajaccio, France, 2006.

[16] Edwards, B.P., "Computer based sun following system." Solar Energy, 21, 491-496, 1978.

[17] Alata M, Al-Nimr M.A., Qaroush Y., "Developing a multipurpose sun tracking system using fuzzy control." Energy Conversion and Management, 46, 1229-1245, 2015.

[18] Batayne, W., Bataineha A., Solimana, I., Hafeesb, S.A., "Investigation of a single-axis discrete solar tracking system for reduced actuations and maximum energy collection" Automation in Construction,98,102-109,2019.
[19] Kuttybay,N.,Mekhilef,S.,Saymbetov,A., Nurgaliyev, M., Meiirkhanov, A., Dosymbetova G., Kopzhan, Z., "An Automated Intelligent Solar Tracking Control System With Adaptive Algorithm for Different Weather Conditions" 2019 IEEE International Conference on Automatic Control and Intelligent Systems (I2CACIS), 29-29 June 2019

[20] Antonanzasa, J., Urracaa, R., Martinez-de-Pisona F.J.,Antonanzas, F., " Optimal solar tracking strategy to increase irradiance in the plane of array under cloudy conditions: A study across Europe" Solar Energy, 163, 122-130, 2018.

[21] Duffie, J.A., and Beckman, W.A., "Solar Engineering of Thermal Processes." John Wiley \& Sons, New Jersey, 2013.

[22] Zadeh, L.A., "Fuzzy sets." Information \& Control, 8, 338-353, 1965.

[23] Messaia A., Mellit A., Guessoumc A., Kalogirou, S.A., "Maximum power point tracking using a GA optimized fuzzy logic controller and its FPGA implementation." Solar Energy, 85(2), 265-277, 2011.

[24] Zimmerman, H.J., "Fuzzy Set Theory and its Applications." Kluwer Academic Publishers, London, 1994.

[25] Dubois, D., and Prade, H., "An introduction to fuzzy systems." Clinica Chimica Acta, 270, 23-29, 1998.

[26] Karr, C.L., and Gentry E.J., "Fuzzy control of pH using genetic algorithms." IEEE Transactions on Fuzzy System, 46-53, 1993.

[27] Goldberg, D.E., "Genetic Algorithms in Search, Optimization, and Machine Learning." AddisonWesley Publishing Company, Inc., 412, 1989.

[28] Lave M.. Kleissl J., Optimum fixed orientations and benefits of tracking for capturing solar radiation in the continental United States, Renewable Energy, 36, 1145-1152, 2011. 